\title{
Forming kinematics analysis of countersinking process
}

\author{
I. Jallouli*, H. Mosbah**, A. Krichen*** \\ *Faculty of Sciences Gafsa, Campus Universitaire Sidi Ahmed Zarrouk, Gafsa University, Tunisia, \\ E-mail: brahimjallouli@yahoo.fr \\ **Faculty of Sciences Sfax, University of Sfax, B.P. 1199, 3031 Sfax, Tunisia, E-mail: hassen.mosbah@yahoo.fr \\ ***Laboratoire de Génie de Production Mécanique et Matériaux, National Engineering School of Sfax, University of \\ Sfax, B.P. 1188, 3032 Sfax, Tunisia, E-mail: Abdelkader.krichen@yahoo.fr
}

cross $^{\text {ref }}$ http://dx.doi.org/10.5755/j01.mech.23.3.14071

\section{Introduction}

Countersinking is a process used in sheet metal forming. This process consists of forming a truncated hole. The obtained internal shape is called countersink and it is used to locate a rivet or screw head. When placed in conical hole, the head of these components must sit flush with the surface with the surrounding material. In practice, the sheet is rigidly clamped around its periphery by a blankholder, and then a truncated punch concentrates deformation to enlarge the side of existing hole Fig. 1. Workpiece performed by countersinking are known by their high mechanical properties and their low cost beside the low material waste and the high productivity.

Due to the conservation of metal volume in plastic domain, countersinking process induces a complex forming kinematics in sheet. Therefore, expansion and retraction of the workpiece can occur. Industrial analyses show that these phenomena affect widely the final shape of the obtained countersink. In addition, some problems can be observed when countersinking process was performed by progressive die. The problems become serious when pilots and punched holes were designed for proper location of sheet. For countersinking process, researches were mainly focused on surface characteristics [1], fatigue life [2-5], the cracking behavior [6] and the characteristics of the riveted link [7]. Up to now, there is a very scarce of literature relating firmly to the countersinking process. In the preliminary study [8] performed by the authors; a FE model has been built and validated experimentally. Jallouli et al., 2011 improved the methodology can be used in determining the parameters of the countersinking process.

In this paper, a finite element (FE) model has been developed to understand forming kinematics. In particular, efforts were concentrated to quantify expansion and retraction phenomena in countersinking process by analyzing the evolution of hole diameter, sheet thickness near countersink and diameter of workpiece. Results were also discussed as a function of blank-holding way.

\section{FE modelling and experiments}

In view of the large number of interacting factors and the complexities of the countersinking process (plasticity, bending, stretching and friction), our attention is focused on developing FE models to lead numerical analysis. The standard version of the FE code ABAQUS has been used. Some experiments were performed to verify the efficiency of the FE models

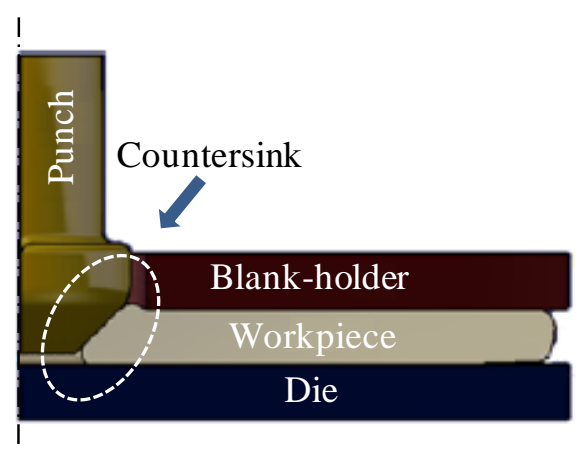

Fig. 1 Countersinking process

\subsection{Workpiece material behavior}

Since the stress field in the workpiece during the countersinking process is mainly in a compression state, the material behavior was characterised under compression test. A special sandwich sample had been made of four disks of sheet which were put together [10]. They have a diameter of $10.5 \mathrm{~mm}$ so that no buckling effect was observed [8]. The tests were carried out under displacement control at a constant rate of $5 \mathrm{~mm}$ per minute. To obtain the stress-strain curve shown in Fig. 2, the conventional analysis assumes a homogeneous state of stresses and strains in the specimen.

For the FE analysis, the metal sheet was assumed to have elastic-plastic behavior with an isotropic hardening rule. The material was assumed to be isotropic and to obey the von Mises yield criterion given by:

$$
f=J_{2}(\underline{\sigma})-R \text {. }
$$

$J_{2}$ denotes the second stress invariant that is defined as follows:

$$
J_{2}(\sigma)=\sqrt{\frac{3}{2} \underline{S}: \underline{S}},
$$

where $\underline{S}$ is the deviatoric part of the Cauchy stress tensor $\underline{\sigma} . R$ denotes the isotropic hardening function that is chosen with form of Swift type:

$$
R=K\left(\varepsilon_{0}+\varepsilon_{p}\right)^{m} \text { with } \varepsilon_{0}=\left(\frac{\sigma_{0}}{K}\right)^{1 / m},
$$

where $\varepsilon_{0}, \sigma_{0}, K$ and $m$ are material parameters for the Swift model. 


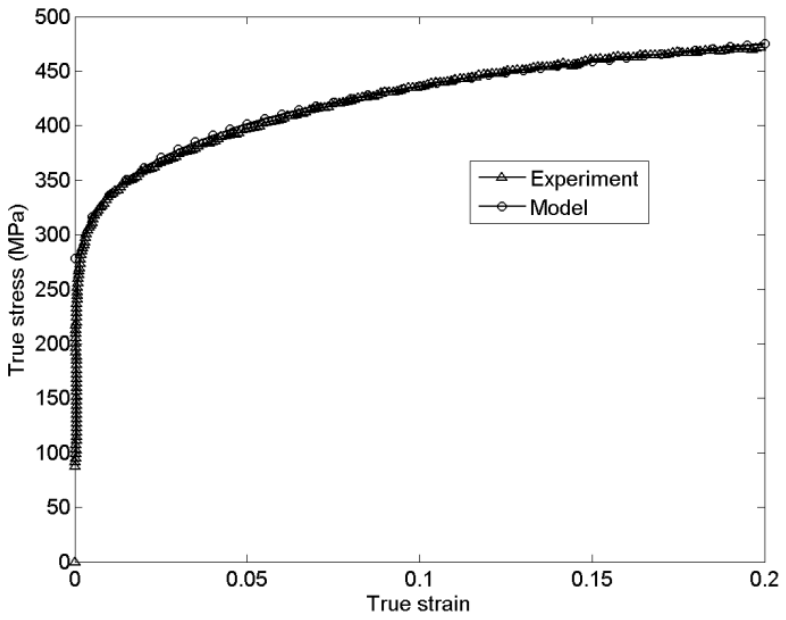

Fig. 2 Material behavior: experimental and simulated stress-strain curves

The evolution of the plastic strain rate is obtained by using the normality rule:

$$
d \varepsilon^{p}=d \lambda \frac{d f}{d \underline{\sigma}}=d \lambda \underline{n}
$$

where $\underline{n}$ gives the direction of the plastic strain increment and $d \lambda$, called the plastic multiplier, determines the magnitude of the plastic strain increment.

The values of the model parameters $\left(\varepsilon_{0}=278 \mathrm{MPa}, K=580 \mathrm{MPa}, m=0.125\right.$ and $\left.\varepsilon_{0}=0.00276\right)$ were obtained by the best fit to the experimental stressstrain curve in the rolling direction as shown in Fig. 2.

\subsection{Countersinking parameters}

To succeed countersinking process, some parameters have to be controlled, especially the tool geometry parameters. A schematic diagram of the countersinking process and the final screw hole is shown in Fig. 3.

The workpiece is a commercial steel sheet with a thickness $e=2.7 \mathrm{~mm}$. It is a washer with an external diameter $d_{r}=30 \mathrm{~mm}$ and an initial hole diameter $d_{i}=6 \mathrm{~mm}$. The cone semi-angle $\varnothing p$ of the truncated punch was set to $90^{\circ}$. To analyze the effect of blank-holding way, three cases were performed: without blank-holder (C1), with fixed blank-holder $(\mathrm{C} 2)$ and with applying a constant displacement $\left(\delta_{b} h=0.01 \mathrm{~mm}\right)$ on the blank-holder $(\mathrm{C} 3)$.

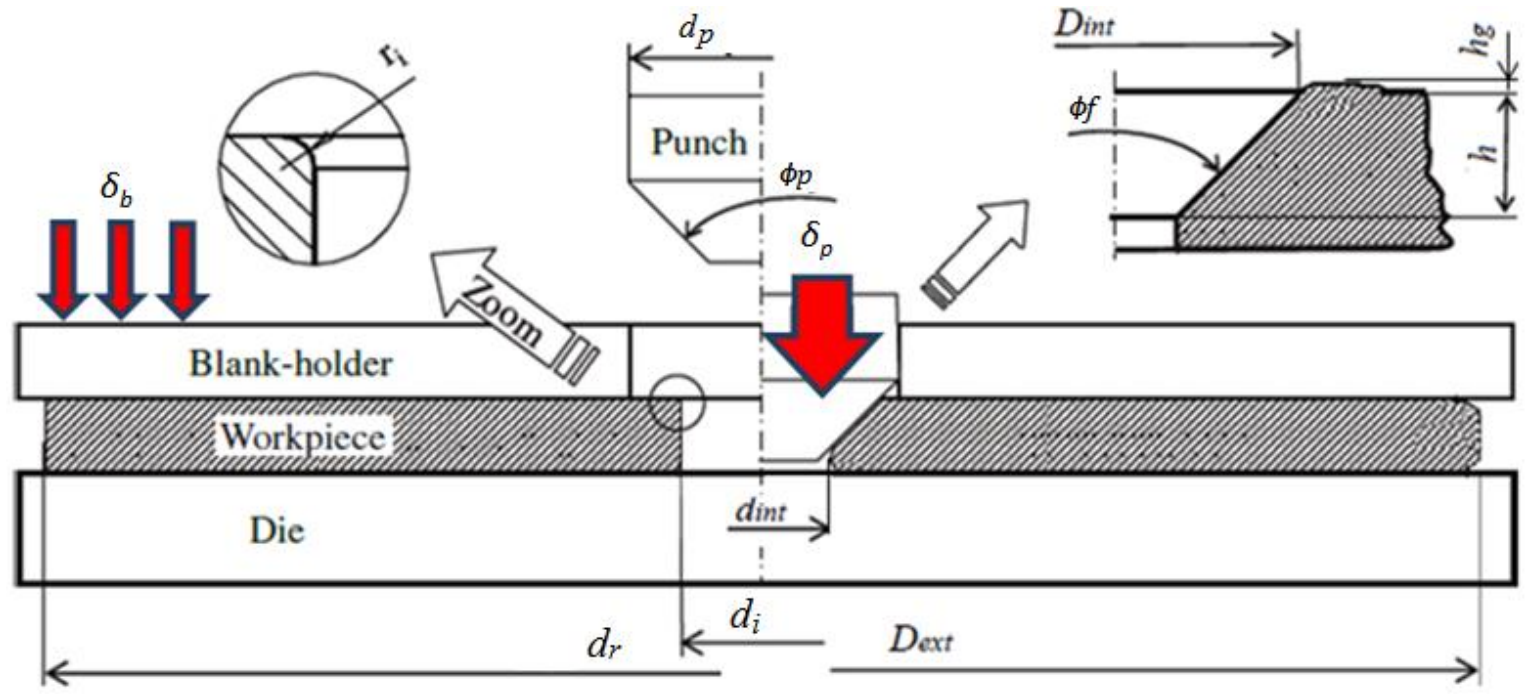

Fig. 3 Geometrical parameters of countersinking process

\subsection{Experiments}

The experimental tool and the workpiece used in this study are shown in Fig. 4.The experiments were curried up with an external diameter $d_{r}$ steel disk. Samples are initially drilled to a diameter di. The punch and the die were made of a tool-steel alloy. They have been solutionised then followed by water quenching. The hardness of this material is equal to $60 \mathrm{HRC}$. The surfaces of the die and the punch were finished by grinding to obtain an average value of the roughness $R a=0.8 \mu \mathrm{m}$

Countersinking tests were carried out with an universal traction-compression testing machine. The tests were performed using displacement control at a constant low rate of the punch equal to $5 \mathrm{~mm}$ per minute. The outputs of displacement gauge, and load cell were continuously stored with data acquisition.

\subsection{FE modeling}

The simulations were performed by the standard version of the FE software ABAQUS. The workpiece was modeled as a deformable body. Die, punch and blankholder were modeled as rigid surfaces. Owing to the revolution symmetry of the geometry and loading, countersinking process were considered as an axisymmetric problem. A typical FE mesh is shown in Fig. 5. A 3-nodes linear axisymmetric triangle hybrid constant pressure element $(\mathrm{CAX} 3 \mathrm{H})$ was used. An automatic mesh generator was used to generate the FE mesh. The elements in the contact area were appropriately refined. Due to the large strain level in the countersinking process, an updated formulation of the mesh was used during the FE calculation. Coulomb's friction law was chosen to solve the frictional effect of the tool-workpiece interfaces. To describe reasonable contact conditions between the tools and the workpiece, a friction coefficient of 0.2 was assumed in the simulation. 


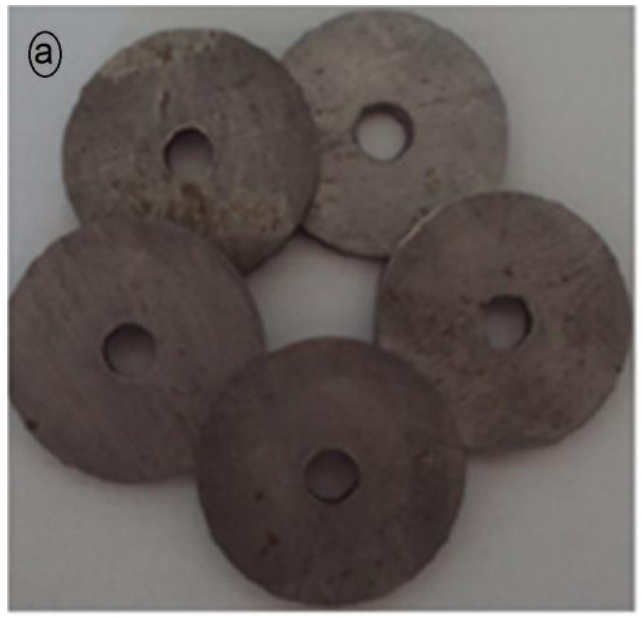

(b)

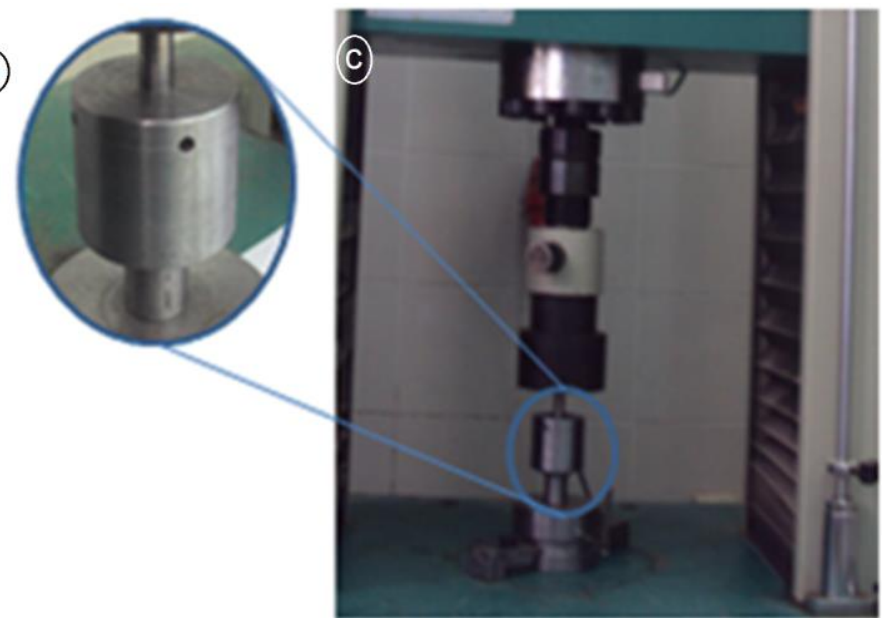

Fig. 4 a - workpiece; b - countersinking tool; $\mathrm{c}$ - testing machine

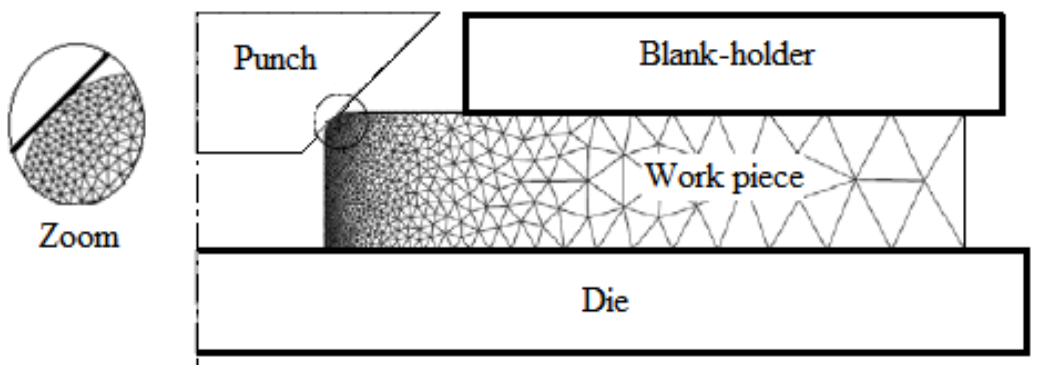

Fig. 5 Typical mesh of countersinking process

\subsection{Experimental validation}

The described FE model is validated by comparison to experimental results in terms of relationship between the punch load and the punch travel (Fig. 6). The FE results can also be used to estimate the countersink shape for a given punch load. Fig. 7 shows a comparison between experimental and simulated countersink. It is worth to note that the results are in good agreement not only in the contact zone but also in the compressed zone under the punch.

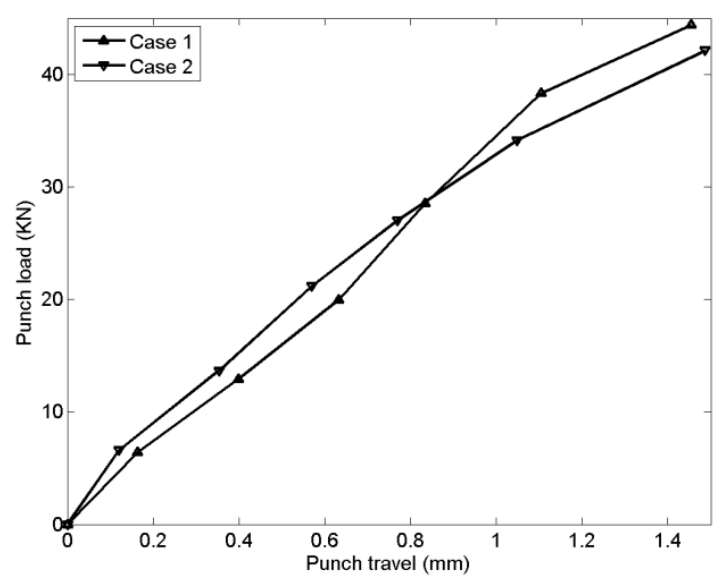

Fig. 6 Punch travel curves, experimental and FE analysis
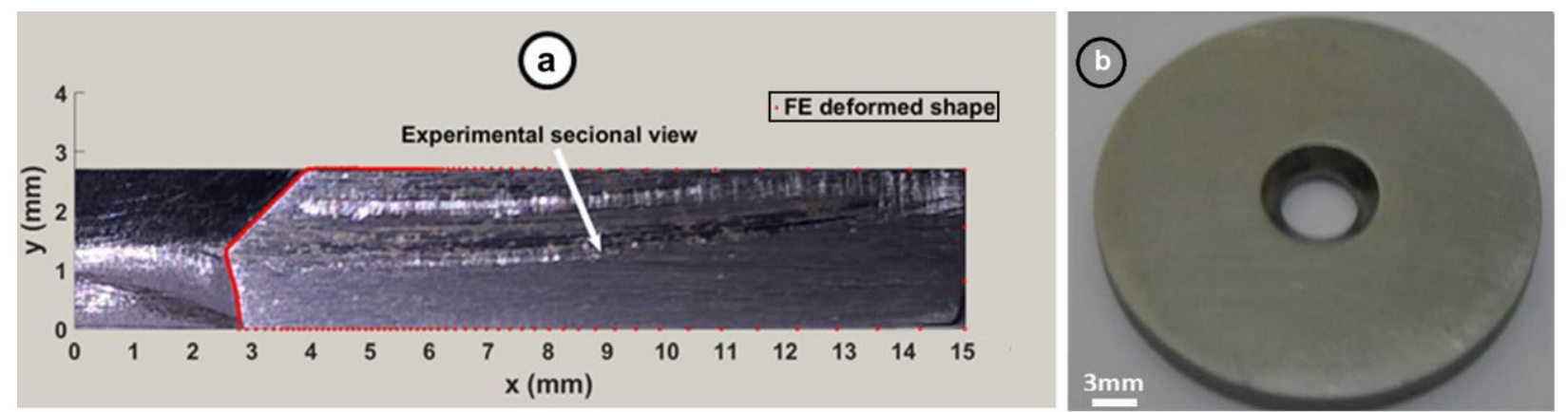

Fig. 7 a - Comparison between FE simulated shape and experimental shape; b - Typical workpiece

\section{Results and discussion}

The investigations were first focused on the pre- diction of the load-displacement relationship. Efforts are secondly concentrated on the forming kinematics during countersinking process. 


\subsection{Punch load-punch displacement}

Punch load versus punch displacement was plotted in Fig. 8 for the three cases (C1, C2 and C3). For each blank-holding case, non-linear relationship was observed. Several parameters cause this observed nonlinearity (nonlinearity of the stress-strain behavior, complexity of the boundary conditions, and nonlinearity of the contact). It was found that the change in blank-holding does not affect the punch load-punch displacement relationship at the beginning of the process. But at the final stage of loading, the punch load increases. Stronger the holding, higher the increase of punch load. Nevertheless, the small change in punch load does not describe the change in forming kinematics.

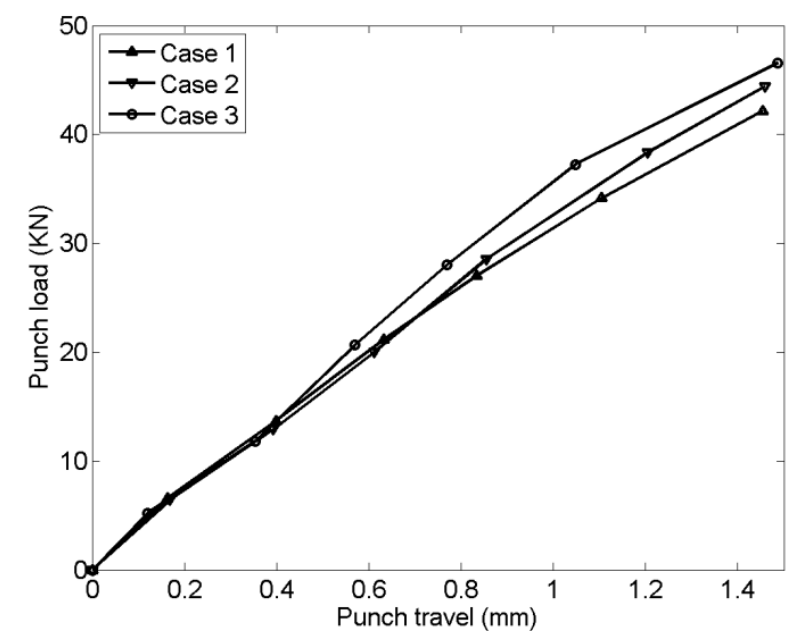

Fig. 8 Punch load versus punch displacement

\subsection{Forming kinematics}

When countersinking was performed without blank-holder $(\mathrm{C} 1)$, the outer edge of the workpiece moves up to a certain level $(\delta M)$. Thus, the final shape reveals a loss of the flatness in the outer edge of the finished product. To accomplish the countersink in the others cases $(\mathrm{C} 2$

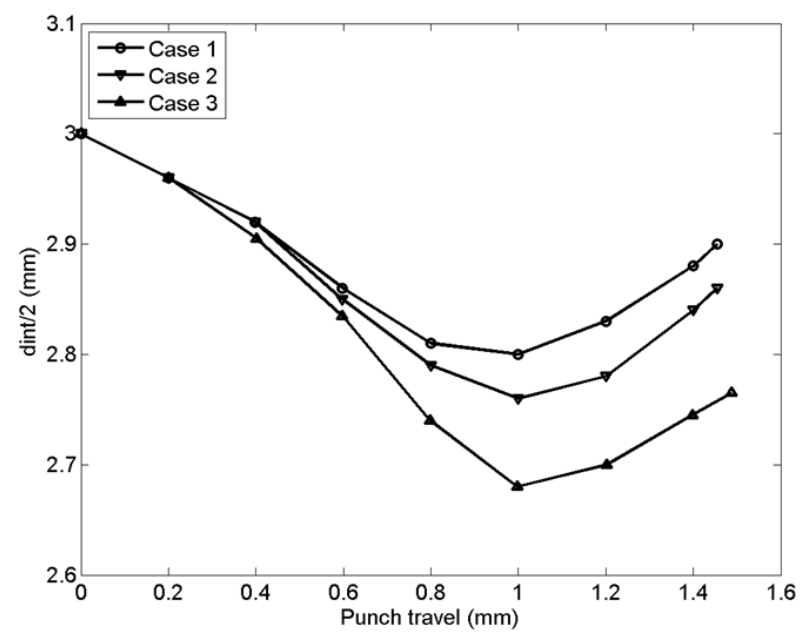

and 3), deformed shape of workpiece shows that the punch pushed the material towards the free regions as shown in Fig. 9.

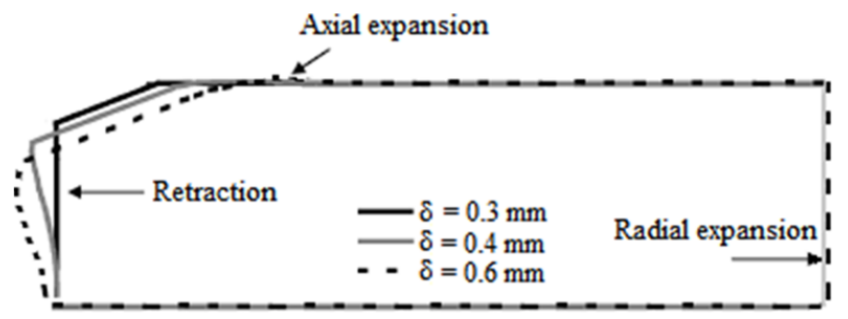

Fig. 9 Deformed shape of workpiece

That is to say, material flows to the regions where no contact area was observed (neither with truncated surface nor with blank-holder). The motion of material toward the center induces retraction of the initial hole. The motion in opposite direction of punch displacement induces axial expansion near the obtained countersink. Finally, sliding under blank-holder produces a radial expansion of the workpiece.

It is clear that analysis of deformed shape gives a good idea about forming kinematics. But it is also important to quantify the observed retraction and expansion and illustrate their evolution as a function of blank-holding conditions. In Figs. 10 and 11 were showed the minimum hole diameter (dint), the maximum sheet thickness (ef) and the increase ( $\Delta$ dext) of the workpiece diameter (dext) during countersinking process respectively. The decrease of (dint) indicated that the retraction of the initial hole was started immediately with the beginning of punch displacement. On the other hand, evolution of (ef) illustrates that axial expansion was started progressively. As regards (4dext) evolution, it illustrates that the radial expansion was radial expansion of workpiece is appeared; both retraction and axial expansion were softened.

Consequently, (dint) was increased and (ef) was decreased.

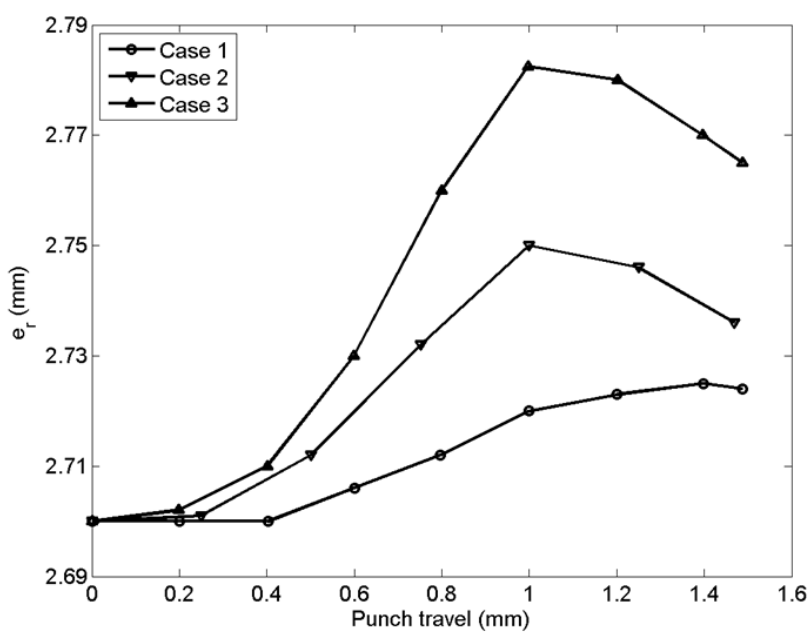

Fig. $10($ dint $),(e f)$ versus punch displacement 


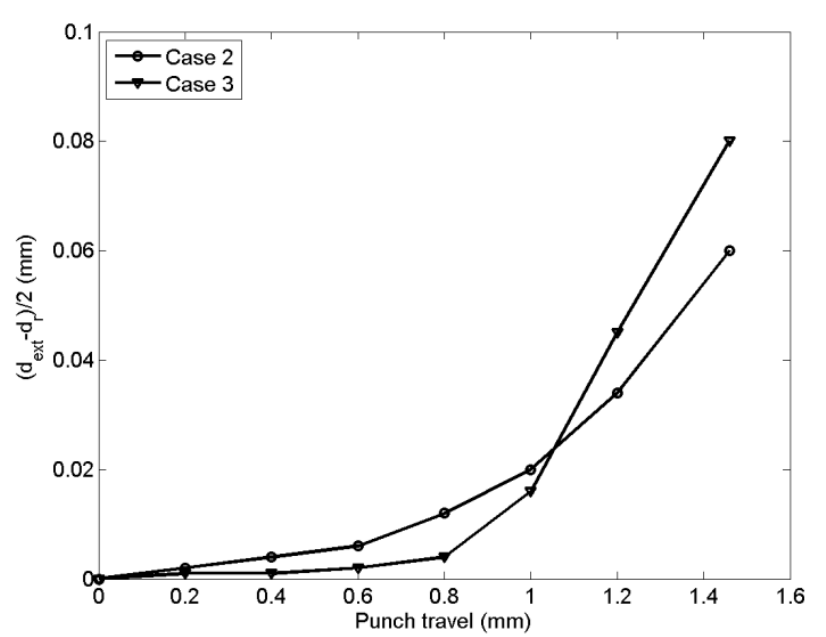

Fig. 11 (dext) versus punch displacement

\subsection{Blank-holding}

It is found that blank-holder avoids the raise of the outer edge of the workpiece and therefore reduces the flatness of the workpiece. In addition, application of blankholding increases the retraction and retards the radial expansion. Table summarizes the maximum variation of the workpiece shape obtained at a punch displacement of about $1.4 \mathrm{~mm}$ and for different blank-holding conditions.

Maximum variation of Workpiece shape obtained Table at punch displacement of about $1.4 \mathrm{~mm}$.

\begin{tabular}{|c|c|c|c|c|}
\hline \multirow{2}{*}{ Case } & \multirow{2}{*}{ Raise of the outer edge } & \multirow{2}{*}{ Retraction } & \multicolumn{2}{|c|}{ Expansion } \\
\cline { 4 - 5 } & & & Axial & Radial \\
\hline C1 & 0.042 & 0.2 & ------ & ------- \\
\hline C2 & ------- & 0.242 & 0.058 & 0.08 \\
\hline C3 & ------- & 0.324 & 0.082 & 0.06 \\
\hline
\end{tabular}

\section{Conclusion}

This study shows that four geometrical changes in the shape of workpiece were observed when countersinking process was performed. Consequently, a complex forming kinematics, which is widely linked to the blankholding conditions, was found. This leads to a difficulty in the prediction of the final shape and proves that the FE model can be an appropriate tool for production and design of sheet parts involving countersink.

The comparison between FE simulations and experiments shows that the developed FE model can be an appropriate tool to predict the punch load, the forming kinematics and the final shape with an acceptable agreement. Finally, it seems interesting to study the effect of the initial anisotropy of the sheet on the FE results. This will be done in future works.

\section{Acknowledgments}

The authors would like to acknowledge the financial support received for the work: Faculty of Sciences Gafsa and Engineering Laboratory of Production Mechanics and Materials. The authors wish to thank the industrial partner, Mr.Mohmed Ejmal from "Les Ateliers Mécaniques Industriels AMI" for his help of experimental apparatus.

\section{References}

1. Ray, M.S.; Matthew, I.R.; Frame, J.W. 1998. Metallic fragments on the surface of miniplates and screws before insertion, British J Oral Maxill Surg 37: 14-18. http://dx.doi.org/10.1054/bjom.1998.0264.

2. Urban, M.R. 2003. Analysis of the fatigue life of riveted sheet metal helicopter airframe joints, Int J Fatigue 25: 1013-1026. http://dx.doi.org/10.1016/j.ijfatigue.2003.08.003.

3. Park, C.Y.; Grandt Jr, A.F.; Suh, J.J. 2006. Stress intensity factors for surface cracks at countersunk holes, Engng. Fract. Mech. 73: 1878-1898. http://dx.doi.org/10.1016/j.engfracmech.2006.02.017.

4. Sohel Rana, M.; Makabe, C.; Fujiwara, G. 2009. The effect of hole shape on the extent of fatigue life improvement by cold expansions, Engng Fail Anal 16: 2081-2090.

http://dx.doi.org/10.1016/j.engfailanal.2009.02.001.

5. S. Sathiya Naarayan; D.V.T.G. Pavan Kumar; Satish Chandra 2009. Implication of unequal rivet load distribution in the failures and damage tolerant design of metal and composite civil aircraft riveted lap joints, Engng Fail Anal 16: 2255-2273. http://dx.doi.org/10.1016/j.engfailanal.2009.03.016.

6. Park, C.J.; Grandt Jr., A.F. 2007. Effect of load transfer on the cracking behavior at a countersunk fastener hole, Int. J. Fatigue 29: 146-157. http://dx.doi.org/10.1016/j.ijfatigue.2006.01.014.

7. Blanchot, V.; Daidie, A. 2006. Riveted assembly modelling: Study and numerical characterization of a riveting process, Mat. Proc. Tech. 180: 201-209. http://dx.doi.org/10.1016/j.jmatprotec.2006.06.005.

8. Krichen, A.; Saï, K.; Bouzid, W. 2008. Finite element modelling of countersinking process, Int. J. Mat. Prod. Tech. 33: 376-386. http://dx.doi.org/10.1504/IJMPT.2008.022516.

9. Jallouli, I.; Krichen, A.; Bougharriou, A.; Saï, K. 2011. Finite Element analysis of countersinking process, International Journal of Manufacturing and Technology 55: 641-648. http://dx.doi.org/10.1007/s00170-010-3090-8.

10. Zhao, H.; Gary, G. 1996. The testing and behaviour modelling of sheet metals at strain rates from 10-4 to 104 S-1, Mat. Sci. and Eng. A 207: 46-50. http://dx.doi.org/10.1016/0921-5093(95)10017-2.

\section{Jallouli, H. Mosbah, A. Krichen}

\section{FORMING KINEMATICS ANALYSIS OF COUNTERSINKING PROCESS}

S u m m a r y

This paper deals with the countersinking process which permits to modify the entrance of an existing drilled hole and to obtain the screw hole countersink. Nevertheless forming kinematics during countersinking process was studied as a function of blank-holding conditions. The effect of blank-holding on the countersinking process was investigated using numerical and experimental analysis. An axisymmetric elasto-plastic finite element model was developed. Four geometrical changes were identified in the 
workpiece shape: the raise of the outer edge, the retraction of hole diameter, the axial expansion of the sheet near the obtained countersink and the radial expansion of workpiece. Finally, a recapitulative table was found to give a range of each parameter at different blank-holding conditions
Keywords: Countersinking Process, forming kinematics, blank-holding

Received January 31, 2016

Accepted June 08, 2017 